\title{
Technical Errors in Intra Oral Radiographs Obtained in Endodontic Department of A Teaching Dental Hospital
}

\author{
Arshad Hasan ${ }^{1}$ \\ BDS, FCPS \\ Farah $\mathbf{N a z}^{2}$ \\ BDS, FCPS \\ Syed Abrar Ali ${ }^{3}$ \\ BDS, FCPS \\ Javeria Ali Khan ${ }^{4}$ \\ BDS, FCPS \\ Batool Ali \\ BDS, FCPS
}

OBJECTIVE: Endodontic procedures rely heavily on correct radiographs. All stages of endodontic care delivery are affected by the quality of resultant image.

Objective of this study was to observe type and frequency of technical errors reported during obtaining intraoral radiographs in the endodontic Department of a teaching hospital.

METHODOLOGY: A total of 600 radiographs were included in this retrospective audit. The radiographs were exposed during routine endodontic procedures. A previously published criteria was used to ascertain the technical quality. SPSS version 21 for windows was used for statistical analysis. Frequency and percentage was calculated as well as chi square test was used to determine associations between variables. $\mathrm{P}<0.05$ was considered significant.

RESULTS: A total of 600 radiographs were included in our study out of which, 185 (30.8\%) were found to be technically correct ( $\mathrm{p}=0.183$ ). Radiographs of mandibular molars presented with most errors $(\mathrm{n}=115,42.4 \%, \mathrm{p}=0.002)$. Errors of technique were more prevalent $(n=383,63.8 \%)$ followed by errors of processing $(n=151,25.2 \%, p=0.000)$. Most common error of technique was positioning error $(n=113,18.8 \%)$ (Table no 3$)$. Most common processing error was yellowing of radiographs $(n=60,10 \%$, $\mathrm{p}=0.003$ ).

CONCLUSION: Performance of undergraduate students in obtaining radiographs was poor. Positioning errors were found to be the most common error while radiographs of mandibular molars were most affected.

KEY WORDS: Dental Radiography, Bisecting Technique, Under graduate Dental Students, Errors of Technique, Processing Errors

HOW TO CITE: Hasan A, Naz F, Ali SA, Khan JA, Ali B. Technical errors in intra oral radiographs obtained in endodontic department of a teaching dental hospital. J Pak Dent Assoc 2019;28(2):50-54.

DOI: https://doi.org/10.25301/JPDA.282.50

Received: 02 January 2019, Accepted: 14 February 2019

\section{INTRODUCTION}

orrect radiographic technique is one of the most important aspects of the clinical endodontic practice. All phases of endodontic care may be effected by correctness of information provided by a well exposed and developed radiograph. Starting from initial diagnosis to the recall appointments of treated patients, a good quality radiograph provides vital information necessary for the success of endodontic treatment. A good quality radiograph

1. Professor, Head of Department, Operative Dentistry, Dow Dental College, DUHS

2. Professor, Head of Department, Operative Dentistry, Dow International Dental College, DUHS.

3. Associate Professor Head of Department, Operative Dentistry, Hamdard College of Medicine and Dentistry, DUHS.

4. Assistant Professor, Department of Operative Dentistry, Dow Dental College, DUHS

5. Assistant Professor, Department of Orthodontics, Dow Dental College, DUHS.

Corresponding author: "Prof. Arshad Hasan" < arshad.hasan@ duhs.edu.pk > may be defined as the one that has a good contrast and brightness, captures the area of interest adequately and is developed adequately. ${ }^{1}$

A radiograph needs to be retaken if the image when seen, does not meet the diagnostic quality criteria. This criteria includes definition, distortion, density and contrast. ${ }^{2}$ These criteria if not met cause errors in image. A radiograph with technical errors leads to incorrect or insufficient information for a quality diagnosis. ${ }^{3}$

A variety of errors maybe categorized into errors of technique and errors of processing. Broadly speaking, the error relating to technique may include, wrong angulation, cone cutting, over or under exposed, blurring, double exposures and positioning errors. While error of processing may include films with scratch marks, deposits of fixing chemicals, finger prints, film bending and other 
discolorations. ${ }^{4}$

In this era of digital radiographs, the teaching hospitals and vast majority of private clinics are still using conventional radiographs due to still prohibitive cost of digital radiographs. ${ }^{5}$ Therefore, this study included only the conventional radiographs.

It may be assumed that given the heavy load of patients in teaching hospitals and variety of level of expertise on workforce, the probability of committing technical and processing mistakes may be high. Gopal et. al. reported upto $45 \%$ radiographs with errors in their study. ${ }^{6}$ While Carvalho reported that $49.4 \%$ radiographs were inadequate in their study. ${ }^{4}$ Elangovan reported $27 \%$ errors in their study. ${ }^{7}$ While Acharya reported that $37 \%$ of their radiographs had technical errors most common of which was positioning of radiograph. ${ }^{8}$ Among local researchers, Ibrahim conducted a comparison of parallel and bisecting angle technique for measuring working length only. ${ }^{9}$ This study did not report on any technical errors.

To the best of our knowledge we were unable find similar study in local literature. It was therefore the objective of our retrospective data analysis, to observe the pattern and frequency of technical errors observed in obtaining intraoral periapical radiographs in an endodontic department of a teaching hospital. The results may be helpful in explaining the radiographers as well as the ones who interpret them in correctly identifying the error and ways to improve the quality of radiograph. This study was conducted on retrospective data from endodontic department of a teaching hospital.

\section{METHODOLOGY}

This retrospective study included radiographs of endodontic procedures performed at the Endodontic department of Hamdard College of Medicine and Dentistry during 2006-2016. An institutional review board (HCM\&D/751/2018) gave approval for the study. Sample size was calculated with OpenEpi online calculator version 3.01. We used the results from a study that reported $37 \%$ errors in its sample. ${ }^{8}$ A sample of 359 was calculated at $95 \%$ confidence level and $80 \%$ power of test. However, we included 600 radiographs to obtain a reasonable representation of variety of errors. All radiographs included in the study that were taken during endodontic procedures in the Endodontic Department during a 10 year period from 2006 to 2016. The radiographs were performed by the under graduate dental students. Bisecting angle technique was used in all cases. Kodak E speed films were used and an X-ray machine with $70 \mathrm{KVa}$ and $10 \mathrm{MA}$ was used. Radiographs were chemically processed. Later, these radiographs were stored in department records. These records were accessed and radiographs were retrieved for the study. We excluded all those radiographs that were taken in other departments of the hospital. Only fully developed radiographs performed and developed by undergraduate students in the OPD of endodontics were included. Included radiographs were digitized using a Nikon D500 digital camera and a $105 \mathrm{~mm}$ macro lens at auto setting. The camera lens assembly was stabilized with a tripod that also helped to produce similar images for each radiographs. Captured images were visualized on a windows based PC using a standard 15 inch LCD monitor. Criteria used to assess the radiographs is given in table no 1 . This criteria was modified from an earlier reported study. ${ }^{4}$

Two calibrated examiners viewed radiographs separately. Calibration was performed by a third person who had more

Table 1: Criteria for assessing radiographs

\begin{tabular}{|c|c|}
\hline $\begin{array}{l}\text { technical } \\
\text { correctness }\end{array}$ & $\begin{array}{l}\text { Sharpness of detail } \\
\text { minimum distortion } \\
\text { correct framing of the film in the region } \\
\text { absence of artefacts } \\
\text { Adequate density and contrast ratio }\end{array}$ \\
\hline \multicolumn{2}{|l|}{ Errors } \\
\hline \multirow[t]{10}{*}{ Errors of Technique } & Cone Cutting \\
\hline & Cutting of apex or crown \\
\hline & Angulation error in horizontal Axis producing overlapping \\
\hline & Angulation error in Vertical Axis producing shortening \\
\hline & Angulation error in Vertical Axis producing elongation \\
\hline & Under exposed \\
\hline & Over exposed \\
\hline & Double Exposure \\
\hline & Blurring \\
\hline & Positioning error \\
\hline \multirow[t]{7}{*}{ Errors of Processing } & Stained \\
\hline & Yellowed \\
\hline & Scratched \\
\hline & Partially revealed \\
\hline & Film Bending \\
\hline & Fingertip marks \\
\hline & Artifacts \\
\hline
\end{tabular}

than 10 years of experience after obtaining his terminal qualification in endodontics. Inter examiner reliability was calculated using Kappa statistics.

\section{STATISTICAL ANALYSIS}

SPSS version 21 was used for statistical analysis. Frequency and percentages were calculated for presence and types of errors. Chi square test of association was used for determining association between type of errors and location of arch at $\mathrm{p}<0.05$.

\section{RESULTS}

We found excellent inter-examiner reliability $(=0.73)$. Frequency of radiographs according to jaw and teeth group 
is presented in table no. 2. A total of 600 radiographs were included in our study that met the inclusion criteria. Out of these, $185(30.8 \%)$ were found to be technically correct

Table 2: Basic Data

\begin{tabular}{|l|l|l|}
\hline & Frequency & Percent \\
\hline maxilla & 315 & 52.5 \\
\hline mandible & 285 & 47.5 \\
\hline Total & 600 & 100.0 \\
\hline anterior & 125 & 20.8 \\
\hline premolar & 204 & 34.0 \\
\hline molar & 271 & 45.2 \\
\hline Total & 600 & 100.0 \\
\hline
\end{tabular}

Table 3: Overall results

\begin{tabular}{|l|l|l|l|l|l|l|}
\hline \multicolumn{2}{|c|}{} & \multicolumn{2}{|l|}{ Teeth } & & \\
\cline { 3 - 5 } & anterior & premolar & molar & Total & $p$ \\
\hline \multirow{3}{*}{ Errors } & yes & 74 & 155 & 187 & 416 & $0.006^{*}$ \\
\cline { 2 - 5 } & no & 51 & 49 & 84 & 184 & \\
\hline Total & 125 & 204 & 271 & 600 & \\
\hline
\end{tabular}

Table 4: Errors of technique, Overall results

\begin{tabular}{|l|l|l|l|}
\hline & Frequency & Percent & $P$ \\
\hline cone cutting & 73 & 12.2 & $0.000^{*}$ \\
\hline cutting of apex or crown & 78 & 13.0 & \\
\hline angulation error in horizontal axis & 11 & 1.8 & \\
\hline shortening & 17 & 2.8 & \\
\hline elongation & 26 & 4.3 & \\
\hline under exposed & 27 & 4.5 & \\
\hline over exposed & 7 & 1.2 & \\
\hline blurring & 31 & 5.2 & \\
\hline positioning error & 113 & 18.8 & \\
Total & 383 & 63.8 & \\
\hline
\end{tabular}

Table 5: Errors of Processing, Overall results

\begin{tabular}{|l|l|l|l|}
\hline & Frequency & Percent & $P$ \\
\hline no error & 449 & 74.8 & $0.003^{*}$ \\
\hline stained & 28 & 4.7 & \\
\hline yellowed & 60 & 10.0 & \\
\hline scratched & 19 & 3.2 & \\
\hline partially revealed & 7 & 1.2 & \\
\hline film bending & 11 & 1.8 & \\
\hline fingertip marks & 15 & 2.5 & \\
\hline artefacts & 11 & 1.8 & \\
\hline Total & 151 & 25.2 & \\
\hline
\end{tabular}

$(\mathrm{p}=0.183)$. Radiographs of molars were found with most errors ( $\mathrm{p}=0.006$ ) (Table no 3 ). Within molars, mandibular molars presented with most errors $(\mathrm{n}=115,42.4 \%, \mathrm{p}=0.002)$. Among the two major categories, errors of technique were

Fig: 1

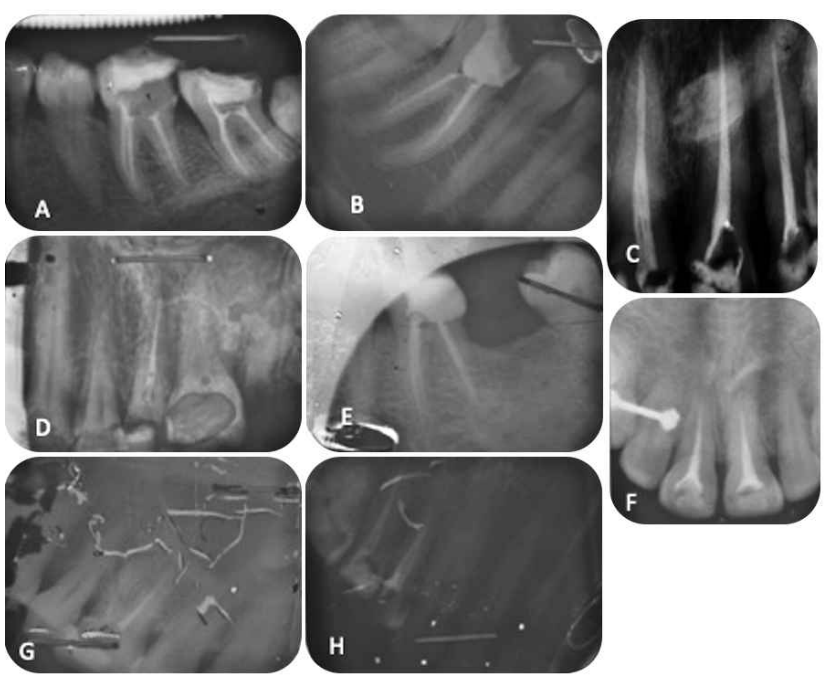

more prevalent $(n=383,63.8 \%)$ followed by errors of processing $(\mathrm{n}=151,25.2 \%, \mathrm{p}=0.000)$. Most common error of technique was positioning error $(\mathrm{n}=113,18.8 \%)$ (Table no 4). Mandibular molars were most commonly affected by positioning errors $(n=49,18.1 \%)$ followed by cutting of crown or apex $(n=26,9.6 \%)$. Most common processing error was yellowing of radiographs $(\mathrm{n}=60,10 \%$, $\mathrm{p}=0.003$ ) (table no 5). Representative images of most common errors can be found in figure no 1 .

Table 6: Errors of technique, Detailed results

\begin{tabular}{|c|c|c|c|c|c|c|c|c|c|}
\hline & \multicolumn{2}{|l|}{ Anterior } & \multirow[b]{2}{*}{ Total } & \multicolumn{2}{|c|}{ Premolar } & \multirow[b]{2}{*}{ Total } & \multicolumn{2}{|l|}{ Molar } & \multirow[b]{2}{*}{ Total } \\
\hline & maxilla & mandible & & maxilla & mandible & & maxilla & mandible & \\
\hline \multirow[t]{2}{*}{ no error } & 56 & 5 & 61 & 31 & 27 & 58 & 21 & 77 & 98 \\
\hline & $44.8 \%$ & $4.0 \%$ & $48.8 \%$ & $15.2 \%$ & $13.2 \%$ & $28.4 \%$ & $7.7 \%$ & $28.4 \%$ & $36.2 \%$ \\
\hline \multirow[t]{2}{*}{ cone cutting } & 7 & 2 & 9 & 25 & 5 & 30 & 22 & 12 & 34 \\
\hline & $5.6 \%$ & $1.6 \%$ & $7.2 \%$ & $12.3 \%$ & $2.5 \%$ & $14.7 \%$ & $8.1 \%$ & $4.4 \%$ & $12.5 \%$ \\
\hline \multirow{2}{*}{$\begin{array}{l}\text { cutting of apex or } \\
\text { crown }\end{array}$} & 10 & 6 & 16 & 13 & 15 & 28 & 8 & 26 & 34 \\
\hline & $8.0 \%$ & $4.8 \%$ & $12.8 \%$ & $6.4 \%$ & $7.4 \%$ & $13.7 \%$ & $3.0 \%$ & $9.6 \%$ & $12.5 \%$ \\
\hline \multirow{2}{*}{$\begin{array}{l}\text { angulation error } \\
\text { in horizontal axis }\end{array}$} & 3 & 0 & 3 & 3 & 1 & 4 & 3 & 1 & 4 \\
\hline & $2.4 \%$ & $0.0 \%$ & $2.4 \%$ & $1.5 \%$ & $.5 \%$ & $2.0 \%$ & $1.1 \%$ & $.4 \%$ & $1.5 \%$ \\
\hline \multirow[t]{2}{*}{ shortening } & 8 & 0 & 8 & 4 & 1 & 5 & 2 & 2 & 4 \\
\hline & $6.4 \%$ & $0.0 \%$ & $6.4 \%$ & $2.0 \%$ & $.5 \%$ & $2.5 \%$ & $.7 \%$ & $.7 \%$ & $1.5 \%$ \\
\hline \multirow[t]{2}{*}{ elongation } & 11 & 0 & 11 & 6 & 5 & 11 & 2 & 2 & 4 \\
\hline & $8.8 \%$ & $0.0 \%$ & $8.8 \%$ & $2.9 \%$ & $2.5 \%$ & $5.4 \%$ & $.7 \%$ & $.7 \%$ & $1.5 \%$ \\
\hline \multirow[t]{2}{*}{ under exposed } & 9 & 1 & 10 & 5 & 7 & 12 & 1 & 4 & 5 \\
\hline & $7.2 \%$ & $.8 \%$ & $8.0 \%$ & $2.5 \%$ & $3.4 \%$ & $5.9 \%$ & $.4 \%$ & $1.5 \%$ & $1.8 \%$ \\
\hline \multirow[t]{2}{*}{ over exposed } & 1 & 0 & 1 & 4 & 0 & 4 & 2 & 0 & 2 \\
\hline & $.8 \%$ & $0.0 \%$ & $.8 \%$ & $2.0 \%$ & $0.0 \%$ & $2.0 \%$ & $.7 \%$ & $0.0 \%$ & $.7 \%$ \\
\hline \multirow[t]{2}{*}{ blurring } & 4 & 1 & 5 & 4 & 10 & 14 & 2 & 10 & 12 \\
\hline & $3.2 \%$ & $.8 \%$ & $4.0 \%$ & $2.0 \%$ & $4.9 \%$ & $6.9 \%$ & $.7 \%$ & $3.7 \%$ & $4.4 \%$ \\
\hline \multirow[t]{2}{*}{ positioning error } & 1 & 0 & 1 & 22 & 16 & 38 & 25 & 49 & 74 \\
\hline & $.8 \%$ & $0.0 \%$ & $.8 \%$ & $10.8 \%$ & $7.8 \%$ & $18.6 \%$ & $9.2 \%$ & $18.1 \%$ & $27.3 \%$ \\
\hline \multirow[t]{2}{*}{ Total } & 110 & 15 & 125 & 117 & 87 & 204 & 88 & 183 & 271 \\
\hline & $88.0 \%$ & $12.0 \%$ & $\begin{array}{l}100.0 \\
\%\end{array}$ & $57.4 \%$ & $42.6 \%$ & $\begin{array}{l}100.0 \\
\%\end{array}$ & $32.5 \%$ & $67.5 \%$ & $100.0 \%$ \\
\hline & & & \multicolumn{3}{|l|}{$p=0.8$} & \multicolumn{3}{|l|}{$\mathrm{p}=0.1$} & $\begin{array}{l}\mathrm{p}=0.00 \\
0\end{array}$ \\
\hline
\end{tabular}


Table 7: Errors of processing, Detailed results

\begin{tabular}{|c|c|c|c|c|c|c|c|c|c|}
\hline & \multicolumn{2}{|l|}{ Anterior } & \multirow[b]{2}{*}{ Total } & \multicolumn{2}{|c|}{ Premolar } & \multirow[b]{2}{*}{ Total } & \multicolumn{2}{|l|}{ Molar } & \multirow[b]{2}{*}{ Total } \\
\hline & maxilla & mandible & & maxilla & mandible & & maxilla & mandible & \\
\hline \multirow[t]{2}{*}{ no error } & 82 & 9 & 91 & 82 & 64 & 146 & 63 & 149 & 212 \\
\hline & $65.6 \%$ & $7.2 \%$ & $72.8 \%$ & $40.2 \%$ & $31.4 \%$ & $71.6 \%$ & $23.2 \%$ & $55.0 \%$ & $78.2 \%$ \\
\hline \multirow[t]{2}{*}{ stained } & 8 & 0 & 8 & 2 & 4 & 6 & 7 & 7 & 14 \\
\hline & $6.4 \%$ & $0.0 \%$ & $6.4 \%$ & $1.0 \%$ & $2.0 \%$ & $2.9 \%$ & $2.6 \%$ & $2.6 \%$ & $5.2 \%$ \\
\hline \multirow[t]{2}{*}{ yellowed } & 4 & 2 & 6 & 17 & 5 & 22 & 11 & 21 & 32 \\
\hline & $3.2 \%$ & $1.6 \%$ & $4.8 \%$ & $8.3 \%$ & $2.5 \%$ & $10.8 \%$ & $4.1 \%$ & $7.7 \%$ & $11.8 \%$ \\
\hline \multirow[t]{2}{*}{ scratched } & 1 & 2 & 3 & 5 & 6 & 11 & 1 & 4 & 5 \\
\hline & $.8 \%$ & $1.6 \%$ & $2.4 \%$ & $2.5 \%$ & $2.9 \%$ & $5.4 \%$ & $.4 \%$ & $1.5 \%$ & $1.8 \%$ \\
\hline \multirow{2}{*}{$\begin{array}{l}\text { partially } \\
\text { revealed }\end{array}$} & 2 & 1 & 3 & 1 & 2 & 3 & 1 & 0 & 1 \\
\hline & $1.6 \%$ & $.8 \%$ & $2.4 \%$ & $.5 \%$ & $1.0 \%$ & $1.5 \%$ & $.4 \%$ & $0.0 \%$ & $.4 \%$ \\
\hline \multirow[t]{2}{*}{ film bending } & 1 & 1 & 2 & 2 & 5 & 7 & 1 & 1 & 2 \\
\hline & $.8 \%$ & $.8 \%$ & $1.6 \%$ & $1.0 \%$ & $2.5 \%$ & $3.4 \%$ & $.4 \%$ & $.4 \%$ & $.7 \%$ \\
\hline $\begin{array}{l}\text { fingertip } \\
\text { marks }\end{array}$ & $\begin{array}{l}5 \\
4.0 \% \\
\end{array}$ & $\begin{array}{l}0 \\
0.0 \%\end{array}$ & $\begin{array}{l}5 \\
4.0 \% \\
\end{array}$ & $\begin{array}{l}4 \\
2.0 \%\end{array}$ & $\begin{array}{l}1 \\
.5 \%\end{array}$ & \begin{tabular}{|l}
5 \\
$2.5 \%$ \\
\end{tabular} & $\begin{array}{l}4 \\
1.5 \% \\
\end{array}$ & $\begin{array}{l}1 \\
.4 \%\end{array}$ & $\begin{array}{l}5 \\
1.8 \% \\
\end{array}$ \\
\hline \multirow[t]{2}{*}{ artifacts } & 7 & 0 & 7 & 4 & 0 & 4 & 0 & 0 & 0 \\
\hline & $5.6 \%$ & $0.0 \%$ & $5.6 \%$ & $2.0 \%$ & $0.0 \%$ & $2.0 \%$ & & & \\
\hline \multirow[t]{2}{*}{ Total } & 110 & 15 & 125 & 117 & 87 & 204 & 88 & 183 & 271 \\
\hline & $88.0 \%$ & $12.0 \%$ & $100.0 \%$ & $57.4 \%$ & $42.6 \%$ & $100.0 \%$ & $32.5 \%$ & $67.5 \%$ & $100.0 \%$ \\
\hline & & & \multicolumn{3}{|l|}{$\mathrm{p}=0.011$} & $\mathrm{p}=0.077$ & & & $p=0.101$ \\
\hline
\end{tabular}

\section{DISCUSSION}

We report on retrospective analysis of 600 radiographs in this study. We found errors of technique, in particular placement errors followed by cutting of crown or apex and cone cutting more often in our samples. Radiographs of mandibular molars were found to be associated with most errors. While molars and premolars were prevalent with placement errors, incisors were mostly error free. Interestingly, errors of processing were less prevalent. Processing errors maybe under reported in this data since poorly processed radiographs may have been discarded real time and this data is retrospective in nature i.e. it is not real time.

Saraswathi reported a similar study from India. ${ }^{6}$ In their study they found cone cut and elongation to be more prevalent than incorrect placement of film in maxillary and mandibular jaw. Our results do not agree with these findings. We found significantly more problems with placement, followed by cone cut with elongation in third place. Reason for this difference maybe due difference in assessment criteria used in that study. In another study from India, Elangovan also found cone cut and elongation more than other errors. ${ }^{7}$ In their study also, undergraduate students performed and processed the radiographs.

Our study agrees with the results of Patel and Mourshed who reported more errors of placement of film. ${ }^{10,11}$ These errors happen when using a bisecting technique, the operator asks the patient to hold the film in mouth with finger. While this might work in maxilla, in mandible due to movement of tongue and cramping of space the chances of incorrect film placement are increased. Our results also agree with those of Peker who also reported film placement as most common error. ${ }^{12}$

Our results partially agree with that of Carvalho who reported more errors of technique than processing. ${ }^{4}$ However, they reported image overlapping as most common error which do not agree with our results. We found most errors in mandibular molar region. However, Zhang found more errors in premolar/ cuspid area. ${ }^{13}$ The reasons for difference in result may be due to difference in technique and a large sample size used by Zhang.

Undergraduate dental students may be limited in their ability to perform radiographs. This fact was reported by Haghnegahdar and it further corroborates our results. ${ }^{14}$ Rushton reported an improvement in identification of radiographic errors by undergraduate students after proper training, which can also help reduce retakes. ${ }^{15}$ Whereas, Ardakani reported an improvement in performance of radiographs by undergraduates after proper training. ${ }^{16}$ Therefore, proper training may help reduce the frequency of errors.

In contrast to our results, Masserat reported a very low frequency of technical errors $(12.9 \%)$ in their study. ${ }^{17}$ Patel also found errors in only $13 \%$ of their sample. ${ }^{18}$

The impact of incorrect radiographs results in repeat of a radiograph. Repeating of a radiographs obtained by conventional processing is time consuming and increases radiation exposure. It also negatively affects the productivity and workflow. It may therefore be logical to assume that dental settings where conventional radiography is used, the operator is forced to accept a poor quality radiograph to avoid delays. This fact can partially explain a high prevalence of errors reported in our study. However, adopting digital radiography may still not reduce the errors as reported in a recent paper where frequency of retakes was still undesirable (1064retakes out total 9397 radiographs). ${ }^{19}$

A study by Acariya studying effect of repeat radiographs revealed that the most common cause of repeat radiographs in their study was placement errors. ${ }^{8}$ Although these results further corroborate our findings, this study was performed mostly on extra oral radiographs and may not be comparable to the results of intra oral radiographs. However, this does raise an interesting point. It may not matter what site is being radiographed, most common error as reported in most of literature and our study is placement error. This facts generates an interesting debate. Should bisecting technique be discarded in favor of more standard parallel technique. It seems bisecting technique in not reproducible and requires fair amount of guess work and may results in a high rate of retake. Parallel technique on the other hand takes the guess work out of practice by using film holders and cone indicators. ${ }^{9,20}$ It is therefore our recommendation that parallel technique should replace bisecting technique in dental settings.

Our study was limited by the fact that it was a retrospective analysis and we could not study the impact of 
repeating of radiographs. We could also not study the improvement in performance of students as they progressed in their clinical rotation. This has been proven previously that experience plays an important role in reducing the errors. We recommend that parallel technique should be used and digital radiography may be adopted to reduce time loss in case of a retake.

\section{CONCLUSION}

Within the limitation of this study performance of undergraduate students in obtaining radiographs was poor. Positioning errors were found to be the most common error while radiographs of mandibular molars were most affected.

\section{CONFLICT OF INTEREST}

None declared

\section{REFERENCES}

1. Whaites E, Drage N, Elsevier (Amsterdam). Essentials of dental radiography and radiology. Edinburgh [etc.: Churchill Livingstone Elsevier; 2015.

2. Hudson T. Radiology standards for primary dental care: report by the Royal College of Radiologists and the National Radiological Protection Board. Radiological Protection Bulletin. 1994;7-9.

3. National Radiological Protection Board. Guidance notes for dental practitioners on the safe use of X-ray equipment. 2001;

4. Carvalho P, Neves A, Medeiros J, Zöllner N, Rosa L, Almeida E. Technical errors in intraoral radiographs performed by undergraduate students. Revista Gaucha De Odontol. 2015;57:151-55.

5. Brian J, Williamson G. Digital radiography in dentistry: a survey of Indiana dentists. Dentomaxillofacial Radiol. 2007;36:18-23. https://doi.org/10.1259/dmfr/18567861

6. K Saraswathi Gopal, N Krishnaraj, M Priya. Faulty radiographs: A retrospective radiographic analysis. Int J Applied Dent Sci. 2018; 4:72-6.

7. Elangovan S, Mahabob MN, Jaishankar S, Kumar BS, Rajendran D. Faulty radiographs: A cross-sectional analysis among dental college students in Namakkal District, Tamil Nadu, India. J Pharm Bioallied Sci. 2016;8:116-18.

8. Acharya S, Pai KM, Acharya S. Repeat film analysis and its implications for quality assurance in dental radiology: An institutional case study. Contemp Clin Dent. 2015;6:392-95.

https://doi.org/10.4103/0976-237X.161898

9. Ibrahim MF, Aziz MS, Maxood A, Khan WU. Comparison Of Paralleling And Bisecting Angle Techniques In Endodontic Working
Length Radiography. Pak Oral Dent J. 2013;33:160-64.

10. Patel JR, Greer DF. Evaluating student progress through error reduction in intraoral radiographic technique. Oral Surgery, Oral Medicine, Oral Pathology. 1986;62:471-74.

https://doi.org/10.1016/0030-4220(86)90300-2

11. Mourshed F. A study of intraoral radiographic errors made by dental students. Oral Surg Oral Med Oral Pathol. 1971;32:824-28. https://doi.org/10.1016/0030-4220(71)90309-4

12. Peker I, Alkurt MT. Evaluation of radiographic errors made by undergraduate dental students in periapical radiography. NY State Dent J. 2009;75:45-8.

13. Zhang ZL, Yang X, Zhao Y. A study of errors of radiography in 10000 intraoral periapical radiographs. [Article in Chinese] Shanghai Kou Qiang Yi Xue. 1995;4:142.

14. Haghnegahdar A, Bronoosh P, Taheri MM, Farjood A. Common intra oral radiographic errors made by dental students. Galen Med J. 2013;16:44-8.

15. Rushton VE, Hirschmann PN, Bearn DR. The effectiveness of undergraduate teaching of the identification of radiographic film faults. Dentomaxillofac Radiol 2005;34:337-42. https://doi.org/10.1259/dmfr/19829457

16. Ardakani FE, Dadsefat R. Investigating the Causes for Repeating Periapical Radiographies in Radiology Department of School of Dentistry and the Effect of Education on its Reduction. Iranian J Med Edu. 2010;9:33-46.

17. Masserat V, Ebrahimi HS, Eil N, Mollashahi J, Naebi M. Evaluation of Frequency of Periapical Radiographic errors in Dental Radiology Department in Zahedan in 2014-2015. Sch J App Med Sci. 2017;5:11215.

18. Patel, J.R. Intraoral radiographic errors. Oral surg oral med oral pathol oral radiol. 1979;48:479-83.

https://doi.org/10.1016/0030-4220(79)90081-1

19. Senior A, Winand C, Ganatra S, Lai H, Alsulfyani N, PachêcoPereira C. Digital Intraoral Imaging Re-Exposure Rates of Dental Students. J Dent Edu. 2018;82:61-8

https://doi.org/10.21815/JDE.018.011

20. Yazdian N. The prevalence of radiographic technical errors, errors radiography and type of error and its related factors in radiographic films produced by students of Islamic Azad University in 2011 (Doctoral dissertation, Doctorate Thesis]. Iran. Dental Branch of Islamic Azad University, 2010.(Persian). 